\title{
Factorial Classification of Consumers for Bamboo- based Products in Haiti: Importance and Perceived Benefits
}

\author{
Daphney Francois ${ }^{1}$, Shu-Yi Liaw ${ }^{2}$, Giang Thi Nguyen $^{3 *}$ \\ ${ }^{1}$ Department of International in Agribusiness Management, National Pingtung University of \\ Science and Technology, Taiwan \\ ${ }^{2}$ Department of Business Administration, Director of Computer Centre, National Pingtung \\ University of Science and Technology, Taiwan \\ ${ }^{3}$ Department of Tropical Agriculture and International Cooperation, National Pingtung \\ University of Science and Technology, Taiwan \\ *Corresponding author's email: nguyenthigiang@tuaf.edu.vn
}

\begin{abstract}
Recently, the use of bamboo as a material in construction and else is very typical almost everywhere in the world. Bamboo stems are able to produce after processing a variety of products ranging from household items to industrial and other applications. The purpose of this study is to identify and classify the homogenous cases that have similar needs and knowledge about the importance application and benefits of bamboo. The questionnaires were completed by 378 respondents in Haiti. The results from K-mean clustering analysis show the three groups identified were namely Functional, Aggressive, and Potential groups. The Functional group was high knowledge about important application factor and low knowledge about benefit factor. While Aggressive group was high in both factors. Besides, the Potential group with the lowest one needing improvement on both factors. This study may suggest to the Haitian population to facilitate investment and promotion of bamboo products in both national and international markets in the country.
\end{abstract}

Keywords: Haiti, bamboo, classification analysis, importance of bamboo, benefits of bamboo

\section{How to Cite:}

Francois, D., Liaw, S. Y., \& Nguyen, G. T. (2021). Factorial classification of consumers for bamboo-based products in Haiti: importance and perceived benefits. International Journal of Business, Management \& Economincs, 2(3). 208 - 224. DOI: https://doi.org/10.47747/ijbme.v2i3.424.

\section{Introduction}

Nowadays, bamboo is considered one of the oldest input used to build almost anywhere in the world. Bamboo can also replace wood in many applications such as construction and especially in industries. Bamboo can also help increase the economy, land degradation and deforestation. Thus, highlight the social and environmental benefits, the benefits of bamboo 
are generally based on the application technology and innovation and treatment of the bamboo involved, the different applications such as cooking food, floor coverings, cooking instruments music, construction, plywood, raw materials, purification as well as its economic costs, agricultural and cultural benefits by assessing the benefits likely to interest national and international businessmen in investing their money in bamboo. The processing of bamboo stems can produce a variety of products ranging from household items to industrial applications and others (Francois \& Liaw, 2019). Most bamboo plants in Asia are relatively common to bridges, scaffolding and dwellings. However, it is used as a temporary external structure material. In many more populated areas, some bamboos provide the appropriate material, often cheap and abundant, to meet the important needs of low-cost housing. Germinating bamboo is also considered an important source of food and delicacy. Over the past decade, bamboo cultivation has played an important role in environmental aspects, social and economic conditions. The technology and innovation of modern processing techniques has transformed bamboo into a series of products that, in many ways, compete with traditional wood products, as well as production costs and product quality. Other benefits are defined as environmental mitigation products such as carbon sequestration, soil stabilization and restoration of degraded lands. This led to a strong desire to grow bamboo around the world (Maxim Lobovikov, 2003). The production of bamboo products is not too common in the national and international market in Haiti. In addition, Haiti is a country highly vulnerable to natural disasters such as hurricanes, landslides, floods, storms and other disasters such as earthquakes. Therefore, it is necessary to have research related to bamboo products to enhance the benefits of bamboo to the Haitian economy. According to several studies to develop the market, it is important to take into account the segmentation, targeting and positioning (STP) that can be considered today as one of the well-known strategic approach of modern marketing.

The aim of this study is to know the targeting of segmentation and market based on the knowledge of consumer responses interested in the importance of the application and benefits of bamboo. The contribution of this study was to identify the application items of bamboo for consumers and businessmen, to evaluate its economic, agricultural, cultural, benefits, and to group the application items, to identify how they can invest in bamboo production in Haiti to attract and interest businessmen to invest in bamboo. In fact, businessmen could use this study to invest and encourage bamboo planting in order to develop the national and international bamboo market in order to develop the country's economy.

\section{Literature Review}

\subsection{Importance of Bamboo Applications in Haiti Within Five Criteria}

The history of bamboo and its various applications dating back to 5000 to 6000 years ago (Zhaohua \& Kobayashi, 2004). Developments in the use of bamboo is the transformation. So a realization took place in China what has committed an awareness of the increasing role that involves Bamboo climate change mitigation, adaptation and development (MAD). The MAD use approach of bamboo has been adopted and applied in various countries (Rockström et al., 2009). Today, with the advancement of technology, nearly 4000 type of commercial products have been made from bamboo or are found available and used almost daily around the world (Singh, 2008). Based on the usefulness and complete transformation, bamboo continue to be regarded as the wood of 21 st century. 
Moreover, the bamboo fibers have come back from nature to nature. In addition, bamboo has been considered as the new type of natural and ecological textile material of production. In the global market, the bamboo trade amounts to $\$ 10$ billion today the organization and global management of bamboo found that it could double the next five years to come (Dayawansa, 2012). In 2002, global trade in bamboo resources was estimated at $\$ 12$ billion. With an annual growth rate of $\$ 2$ billion, total trade in bamboo resources will reach about $\$ 20$ billion by 2015 (Dayawansa, 2012). Worldwide, bamboo is expected for the development of many livelihoods and mitigation of environmental and technological, socially problems. Given the growing popularity of bamboo in the industrial sector and its role in the MAD challenge, most countries have therefore undertaken to invest not only in the production of bamboo but also in the processing of bamboo to strengthen its role in many processes through industrial production (Pandey \& Shyamasundar, 2008).

Haiti is referred to as the bamboo country. Bamboo can also replace wood in many applications such as construction and especially in industries. Bamboo can also help increase the economy, land degradation and deforestation. Thus, highlight the social and environmental benefits, the benefits of bamboo are generally based on the application technology and innovation and treatments of the bamboo involved, the different applications such as cooking food, floor coverings, cooking instruments music, construction, plywood, raw materials, purification as well as its economic costs agricultural, and cultural benefits by assessing the benefits likely to interest national and international businessmen in investing their money in bamboo susceptible to natural disasters because of its geographical position, its level of deforestation, and its experience with the high number of hurricanes every year. Around 20 to 40 million hectares tons of mountain soil are carried away and thousands of hectares remain of their layer. A result of a satellite photography program in 2002 showed that there was only 1.25 million hectares of forest data left in the country. In order to remedy to this situation, the Ministry of Natural Resources and Rural Development (MARNDR) jointly with the financing of the Haitian and Taiwanese governments has set up a project: The Federation Association Native Coffee-farmers (FACN) with farmers' association federation whose main objective is support for the production and marketing of coffee and bamboo (MRND). The importance of application bamboo in Haiti is very important, based on the different things we can do with the bamboo; so far all around the world, especially in Asian countries, bamboo is very used. One of the major raw materials being promoted for use in the development of the textile industry is bamboo. Earlier efforts to reforest the country have shown that bamboo was burned in Haiti by the US Agency in Haiti, including marmalade and several parties in the country, the project was to plant 10,000 hectares of bamboo by 2019 to generate 150,000 tons of dry bamboo annually (Ogunwusi, 2013). This would lead to an increase of 10,000 jobs, which can be direct or indirect. So we come with interest in the development and processing of bamboo for the country. And Haiti, we find many applications such as: houses, bamboo beds, chairs and tables.

In Bamboo, which are the most common, and with other new applications, the country may have another opportunity to develop national and international markets. We attribute five criteria of importance application for the country as follows:

Profitability: the manufacture of bamboo products leads to high quality that would allow us to fight against food insecurity in different rural areas of the country. As a result, and according to previous research, there is economic, social and cultural importance in bamboo production areas, which makes it possible to rank it second only to agriculture in village production 
systems. Compared with other forms of natural resource use, the bamboo sector is highly profitable and requires little capital investment and, as a result, monthly profit margins are relatively high.

Feasible: Bamboo is considered a versatile group of species with multiple uses for sociocultural and industrial (Lobovikov, Schoene, \& Yping, 2012). Speaking of the feasibility of bamboo for the country we take into account the bamboo products that are considered as alternative materials for production. The American industry in Haiti, whose mission was to plant bamboo across the country, has always been very stable and robust because of its commitment to quality. Therefore this high quality is at the cost of large quantities of waste largely burned to heat the facilities. And with the recent surge in corporate responsibility for the total life cycle of their products and the push for increased sustainability, bamboo has been viewed as a viable resource as a partial or full replacement. Prototypes of bamboo chopsticks were made using a technique described as radial lamination to increase the overall stiffness that is crucial for the functionality of a rod and an economic analysis was performed. So it is concluded with the feasibility of its hard-core application of the environment and the technology of bamboo included the global perspective of the use of bamboo as an alternative for the country (Chen, Zhou, \& Zhang, 2014).

Acceptable: The benefits of bamboo as a plant are numerous; and we can say that the placement of bamboo is cheaper to plant, they can grow very fast and can be harvested using less fossil fuels. Even when the problems of sustainability and resistance are resolved, the question of acceptability remains. A bamboo construction does not need to be "low cost": an inventive design and the use of other locally available materials in the cultural context can make the building desirable rather than simply acceptable. For example, in Central America, there are several regions with a long tradition of bamboo construction, bamboo buildings of all kinds, the price of bamboo consumption ranging from a few hundred dollars to a few million. In Ghana, the shortage of affordable housing is one of the most serious social problems related to the country's economic situation. The backlog of housing is already 420,000 units and is growing every year by 120,000 units. In Haiti, speaking of the bamboo issue is almost irreproachable in the face of the various problems that overcome the country and the key advantages that we can draw with the bamboo and all its application and we can say that with bamboo we take a particular importance by offering an ecological alternative to declining wood products, high-energy materials, petroleum-based plastics and expensive imports to the country.

Available: Marketing involves developing bamboo to transform the current process of selling bamboo products. The availability of the bamboo refers to the different applications that can be profitable in relation to the number of elements such as functionality, validity and expenses that must be taken into account when choosing a building material. The design of the bamboo can be considered as natural and unique, it is hollow inside and the fibers extend longitudinally. As a result, the mass of material required is less than that of wood with a larger material mass cross section. When considering the bearing mass, it functions as a section of form. The operation of the bamboo can be related to the requirements of the building. If the bamboo is planting Bamboo growing in a box takes a square shape and can be used to connect objects. It can be folded after being freshly cut and remains in this form after drying. Some bamboo species have the same strength ratio of steel and almost double the compression ratio of concrete. The 1999 earthquake in Colombia was marked by the destruction of all concrete buildings, but bamboo houses remained intact and were not 
affected by the earthquake. In conclusion we can say that giving importance to the benefits of bamboo applications can be linked with the sustainable development of a country.

Success: According to (András Darabant, Prem Bahadur Rai, Christina Lynn Staudhammer, \& Tshewang Dorji, 2016) regional bamboo companies may reduce with success extreme poverty in development countries. Having large economic potential, in terms of success, we can talk about the performance and price of bamboo products that can be combined with other woods. By using the bamboo in the panes and the use of composite materials. Technically speaking bamboo can replace wood, concrete and why not steel in many uses. However, the agricultural sector remains the largest consumer of bamboo products. In addition, bamboo items are still widely used everywhere. Bamboo houses are often found in many types of houses, for example, bamboo houses, traditional houses, which use bamboo stems as a basic building material, and modern prefabricated houses.

\subsection{Bamboo Benefits Within Five Criteria}

The bamboo plant is very resistant that does not need pesticides or herbicides to grow. It can also grow in several different environments. The bamboo plant grows quickly, and once cut it can repel itself from its roots. The bamboo plant can also produce 35\% oxygen equivalent to several other trees. Based on its different potentialities of bamboo and its advantages, this study attributes five aspects with the advantages benefit of bamboo: Economic aspects, social aspects, environmental aspects, technological aspects, and security aspects.

Economic aspects of bamboo: According to some researchers about the economy of bamboo plantation and the harvesting are both positive and negative economic effects in the geographical areas of growth. The exploitation of bamboo leads to a series of incomegenerating activities, especially in rural areas where people are considering jobs for those who carry out these activities, as well as jobs for small and medium-sized enterprises. The most important economic benefits for most bamboo applications are the commercial transactions of their bamboo products. According to the results, most communities in which bamboo is grown commercially benefit from infrastructure such as houses, roads, electricity, schools, hospitals, and good quality water. Some local communities have benefited from community development projects in these industries, allowing them to improve their conditions through these benefits. As bamboo production has become lucrative, most farmers are now converting their cultivated land to bamboo farms, although they are grown by a large majority of people. Most people would have to travel long distances to find land that is useful for cultivation and safe. By definition, the economic benefits of the bamboo outweigh the negative effects of the assessment to date in the communities in which they spread. People from many communities as well as people in rural areas have had a tremendous impact on their economic life, infrastructure and livelihoods. It should therefore be taken into account that the income generated by agricultural products had decreased in areas where the commercial cultivation of bamboo is increasing more than the other income generating activities which entail wage labor, which can be increased in bamboo enterprises.

Social aspects of bamboo: The social aspect of bamboo involved in the bamboo plantation, as well as the bamboo processing harvest that generally brought many benefits that may be more social benefits to the farmers and commercial communities of bamboo production. Bamboo is commonly Applied "poor man's wood" because it is generally useful for the poor classes at often very low costs in recent years. During its last years the production of the bamboo mainly in many countries in Asia it development several other application in direct port with a 
population grade for example the purification of the water is one of the commons problems in the rural areas. Social development of investment management system bamboo and production have highly valued and demonstrated. The bamboo plant that is grown for commercial purposes can be transformed in a positive way, resulting in a huge income from its products. This is thanks to the new development of industries and wood processing. Several investors, especially in the Republic of China in Linan County, have shown that bamboo farming is able to change all the communities from the poorest to the richest. Bamboo plantations can be guided by individual farmers, who use other than basic tools for harvesting. And with processing plants for shoots, stubble, flooring, panels and many other products for domestic and foreign markets, bamboo has become indispensable in improving most of the social development license available to the people, to the communities and nations that are dedicated to growing and processing commercially and this has been demonstrated in most Asian and South American countries.

Environmental aspects of bamboo: Regarding the environmental and ecological benefits of bamboo examines the impacts of planting, local forests, water resources, non-wood forest products and biodiversity. Many environmental cases that have been encountered globally in recent years indicate that the environmental and ecological benefits of bamboo have generally demonstrated that current development models are not sustainable. These indications may highlight the need to introduce environmentally-friendly and ecologically sound development processes through industrial development. In addition, our more precarious environment in Haiti has suffered many disasters resulting from climate change resulting in floods resulting in loss of life and property, and also in many countries (Akwade \& Akinlabi, 2016). The climate change is becoming a global phenomenon considering the above, modes of production and consumption activities, including international trade. According to ITTO's anthropogenic emissions (2005), deforestation, which accounts for nearly $20 \%$ of all, is one of the main causes of climate change. As a result, global development initiatives minimize the role of forest resources as industrial inputs. The production and use of bamboo to the point of cultivating high-performance substitutes such as boards and accessories are in the process of industrial production. The management of bamboo creates a peculiarity to the problems of few biotical inputs, as few pest and disease problems have been reported. As a global issue, deforestation can result in a significant reduction in forest cover due to the high dependence on wood species for domestic processing and export. Bamboo has finally contributed to the social needs of its traders and even more to its producers by improving the development of the amenities of their communities. We can also identify some negative effects on the environment when natural forests are destroyed to pave the way for bamboo cultivation. Although most chemicals used in other plants such as pesticides and herbicides used in plantations, seep into the soil and water bodies, causing the death of livestock and other aquatic species.

Technological aspects of bamboo: The use of bamboo can be varied and adaptable in anatomical, structural and chemical forms. Usually, it is able to replace technically and commercially wood, but also plastics, steel, and cement, as well as building materials. Composites of bamboo in structural applications and products are very popular. Based on the sound of bamboo technologies that can highlights product innovation and the application of technical and scientific skills. Bamboo is an important vector and sustainable development that can, increasing economic opportunities, as well as income and employment, mainly in the relatively underdeveloped regions of the globe. Bamboo is also another ecological alternative, 
considered as a material that lends itself easily to simple and innovative processing technologies (Mudjanarko \& Mayestino, 2017). For instance, it further enhanced through the application of modern engineering techniques, it can be processed into modern products. Bamboo shoots are succulent and nutritious with a $100 \mathrm{~g}$ portion containing 0.5 to $0.77 \mathrm{~g}$ fiber, 81 to $96 \mathrm{mg}$ calcium, 0.5 to $1.7 \mathrm{mg}$ iron, 3.2 to $5.7 \mathrm{mg}$ vitamin $\mathrm{C}, 0.07$ to $0.14 \mathrm{mg}$ vitamin $\mathrm{B} 1,1.3$ to $2.3 \mathrm{~g}$ protein, 4.2 to $6.1 \mathrm{~g}$ carbohydrates, 42 to $59 \mathrm{mg}$ phosphorus and 1.8 to $4.1 \mathrm{~g}$ glucose (Phimmachanh, Ying, \& Beckline, 2015). Among the different species, some of them have significant amounts of potassium and vitamin A. In bamboo shoots, up to 17 amino acids can be found, such as saccharin, ceramic acid and glutamic acid. Bamboo also has the potential to serve as a renewable energy source (biofuel) that can be exploited and harvested sustainably and commercially. Innovation of bamboo charcoal could make handling and transport sufficiently efficient to make it an economically attractive small-scale industrial activity. Moreover. bamboos contain $\mathrm{CO}_{2}$-neutral energy, which can also replace fossil fuels. By managing or harvesting fast-growing bamboo and subsequently replacing it with higher value trees. Achieving a sustainable forest value, both in financial terms and in terms of biodiversity (McNeely, 1999).

Security Aspects of Bamboo: In most African countries in particular, environmental degradation has a serious global dimension, affecting the security of nations. In almost every area, environmental security simplifies the environmental problems that threaten the national security of a country. So, in response to the population's need for the bamboo plantation, a report on the deterioration of the environment has been issued to say that all environmental events are counterproductive to national security. Among the different issues such as deforestation, destruction of water resources, natural forest products and loss of biodiversity have taken on serious dimensions and may threaten the security of a country according to (Ganado, Undan, \& Valentino, 2016). It may be said that one of the six classified threats that the world must now address is environmental degradation, and the United Nations has also recognized the urgency of tackling these problems in the coming decades. United Nations (2004). Bamboo is also useful for controlling soil erosion and also for many industrial and construction uses. Bamboo can grow well on steep slopes, road embankments, gullies or on the shores of ponds and ponds streams. In Japan, in one mountain called Hakone-Yama, the bamboo community of Sasa and in the dantrocalamus dispersed in the high mountains, 1,000 $\mathrm{m}$ above sea level, causing little loss in water and soil. Brazil has also introduced Bambusa blumeana and Phyllostachys pubescens to control soil erosion, and to prevent nutrient loss and improve soil structure (Ben-zhi, Mao-yi, Jin-zhong, Xiao-sheng, \& Zheng-cai, 2005). Bamboo has several beneficial and safe characteristics mainly to control soil erosion of one of the extended fibrous root system, its connected rhizome system included the leafy mulch it can produce on the soil surface, its relatively dense foliage which protects against pouring rain and its habit of producing new culms from the basement rhizomes that gives access to harvest without disturbing the soil.

\section{Research Method}

\subsection{Data Collection}

This study used questionnaires containing objective questions about the importance attached to the question and the benefits of bamboo based on the consumer's response. Random selection was applied in this study to select interview individuals who have consumed products made from bamboo. The questionnaire was divided into four sections. The first 
Vol. 2, No. 3, August 2021

section to assess the application of bamboo. The second section deals with important of bamboo. The third section to assess the benefits of bamboo. The five-point Likert scale ranging from 1 for "strongly disagree" to 5 for "strongly agree" was used in second and third sections. Section 4 referred to personal information such as gender, age, education, occupation, and employment status.

The questionnaire reliability and validity were assessed through a pilot test on 30 respondents. Cronbach's alpha was used to evaluate internal consistency within the data. The pre-test analysis revealed Cronbach alpha values for all questionnaire items lowest equal 0.74 that greater than 0.7. According to the recommendation by Hair, Black, Babin, and Anderson (2014), a Cronbach's alpha value higher 0.7 indicates good internal consistency of a questionnaire item in the data collection process. Consequently, some words were rephrased accordingly based on the respondents' suggestions. Then, the official survey was conducted by face-to-face interviews with bamboo product consumers in Haiti. Finally, 378 usable responses were received in first quarter of this year.

According to the descriptive statistical results presented in Table 1, in this study we used a sample of respondents aged less than 50. Majority (45.5\%) of the sample had high school education with $31.7 \%$ holding Bachelor's degrees. The most of respondents were women $(53.2 \%)$, aged 31 to $40(61.9 \%)$, and public sector employees (31.7\%).

Table 1. Descriptive demographic $(n=378)$

\begin{tabular}{cccc}
\hline Variables & Group & Frequency & Percent (\%) \\
\hline \multirow{2}{*}{ Gender } & Male & 177 & 46.8 \\
& Female & 201 & 53.2 \\
Age & Below 30 & 67 & 17.7 \\
& $31-40$ & 234 & 61.9 \\
& $41-50$ & 77 & 20.4 \\
Occupation & Blow high school & 56 & 14.8 \\
& High school & 172 & 45.5 \\
& Bachelor's degree & 120 & 31.7 \\
& Higher education & 30 & 7.9 \\
& Unemployed & 83 & 22.0 \\
Employment status & Manual & 71 & 10.8 \\
& Private employee & 120 & 19.8 \\
& Public employee & 59 & 31.7 \\
& Others & & 15.6 \\
\hline
\end{tabular}

\subsection{Measurement}

This study used ten items considered five items describing the importance of bamboo and five items for the perceived benefits of bamboo. From the importance application we have: profitable, feasible, acceptable, available, and success that described in the questionnaire by statements may explain the variable measurement (Darabant, Rai, Staudhammer, \& Dorji, 2016; Lobovikov, 2003). From the perceived benefit we have: economic, social, environment, technology, and security also describe by some statements may explain the variables measurement (Ben-zhi et al., 2005; Lobovikov, 2003; Scurlock, Dayton, \& Hames, 2000). 
Vol. 2, No. 3, August 2021

\subsection{Data Analysis}

The statistical package for social sciences (SPSS 22.0) software and Statistica 13 software were used in this study. The descriptive analysis depending on the demographic characteristics of the sample was tested by the SPSS software. Exploratory factor analysis (EFA) was used to explore the underlying structure of a set of items and the measurement elements of the reliability and Cronbach alpha coefficients were also tested. Cluster analysis is a genetic label to apply to a set of techniques in order to classify similar group entities from characteristics (categorical or measured) possessed by the entities.

\section{Results and discussion}

\subsection{Evaluation Different Application of Bamboo}

The study presented 20 applications of bamboo in different fields (Appendix 1) to assess consumer feedback on important applications of bamboo. The results in Table 2 show that consumers rate bamboo's most important applications in areas such as: bamboo panels (38.62\%), bamboo housing (30.95\%), bamboo charcoal $(26.46 \%)$, bamboo bed sheet (24.87\%), and bamboo instruments (24.07\%). Many different applications of bamboo are rated as less important by consumers, for example, bamboo garden $(5.56 \%)$, bamboo crafts $(5.29 \%)$, bamboo matting $(4.76 \%)$, and bamboo paint brushes $(3.7 \%)$. This may lead to low development and consumption of some bamboo products in Haiti. Therefore, manufacturers should have many programs to promote products made from bamboo.

Table 2. Frequencies Bamboo Applications from Consumer's Response .

\begin{tabular}{lcclrc}
\hline \multicolumn{1}{c}{ Bamboo application } & Freq. & Per. $(\%)$ & Bamboo application & Freq. & Per. (\%) \\
\hline Bamboo Panels & 146 & 38.62 & Bamboo Furniture & 42 & 11.11 \\
Bamboo Housing & 117 & 30.95 & Bamboo Cutting boards & 42 & 11.11 \\
Bamboo Charcoal & 100 & 26.46 & Bamboo Fuel & 41 & 10.85 \\
Bamboo Bed sheets & 94 & 24.87 & Bamboo Flooring & 37 & 9.79 \\
Bamboo Instruments & 91 & 24.07 & Bamboo Paper & 26 & 6.88 \\
Bamboo Food & 85 & 22.49 & Bamboo Blinds & 23 & 6.08 \\
Bamboo Pub & 60 & 15.87 & Bamboo Garden & 21 & 5.56 \\
Bamboo Fabrics & 57 & 15.08 & Bamboo Crafts & 20 & 5.29 \\
Bamboo Raw materials & 53 & 14.02 & Bamboo Matting & 18 & 4.76 \\
Bamboo Clothing & 47 & 12.43 & Bamboo Paint brushes & 14 & 3.70 \\
\hline
\end{tabular}

\subsection{Grouping Bamboo Consumers in Haiti}

The present study uses the k mean algorithm to group bamboo consumers in Haiti based on the importance and benefits received. First, we conduct testing of reliability and validity among the constructs and determine the number of clusters.

According to several studies, the most common method consisted in identifying the alpha coefficient of a given construction that could study the internal coherence of the indicators of each studied construction (Henseler, Ringle, \& Sinkovics, 2009). The Table 3 below show, the Cronbach's $\alpha$ coefficient ranged from 0.897 to 0.907 . According to (Nunnally \& Bernstein, 1994) suggested the level Cronbach's $\alpha$ beyond 0.70 therefore, the values 
Vol. 2, No. 3, August 2021

obtained from the test analysis suggested that all constructs were consistent and reliable internally.

Table 3. Testing of reliability and validity among the constructs

\begin{tabular}{llccc}
\hline \multicolumn{1}{c}{ Constructs } & \multicolumn{1}{c}{ Items } & Main factors & Cronbach's $\alpha$ \\
\hline Importance & Acceptable & 0.989 & & \\
application & Profitability & 0.988 & & 0.897 \\
& Available & 0.987 & & \\
& Feasibility & 0.985 & & \\
& Success & 0.931 & & 0.907 \\
Perceived & Environment & & 0.934 & \\
benefits & Security & & 0.923 & \\
& Technology & & 0.909 & \\
& Economic & & 0.900 & \\
& Social & & 0.882 & \\
\hline
\end{tabular}

This study use K-means clustering like a partitioning method that can divides the observations of data into $\mathrm{k}$ mutually exclusive clusters. The empirical identification of categories and clusters is based on the identification of the subgroup that has a related vector variable profile. The Euclidean distance matrix between rows is calculated. Based on Akaike's information criterion (AIC) value to determine the number of cluster. In Figure 1 show that the total of 10 clusters and the value of AIC from 4 clusters to 10 clusters did not change significantly. Therefore, the number of clusters of 3 is considered to be the most appropriate in this study (Hu \& Xu, 2003). Therefore, the consumers are classified into 3 groups via the k-means clustering method based on importance application and perceived benefits factors discussed considering that is the appropriate number of the group that fits the study objective.

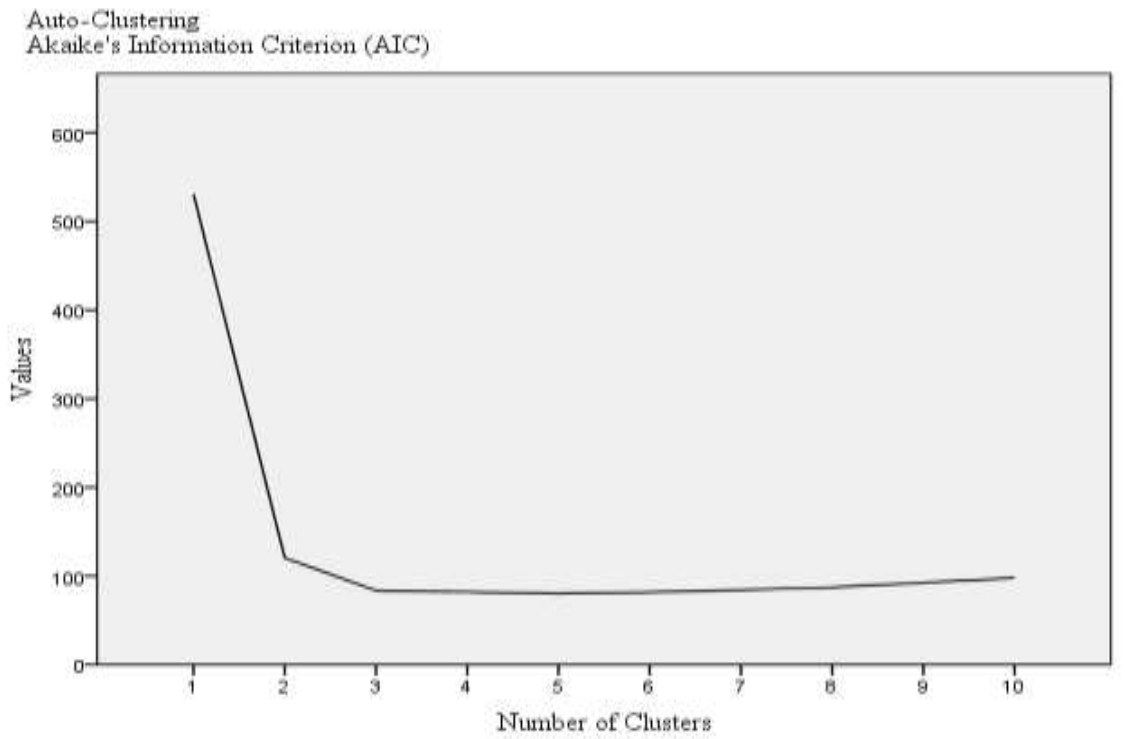

Figure 1. Akaike's Information Criterion (AIC) to define the number of clusters 
Vol. 2, No. 3, August 2021

In Table 4, the initial center sort distance and the observation at constant distance with the respondents' responses have been clustered into three groups from the consumer views. Based on the characteristics of consumers in each cluster, three clusters were established, namely, Functional group, Aggressive group, and Potential group.

Table 4. Cluster center and members

\begin{tabular}{cccc}
\hline Cluster (Members) & $\begin{array}{c}\text { Cluster 1 } \\
(\mathrm{n}=49)\end{array}$ & $\begin{array}{c}\text { Cluster 2 } \\
(\mathrm{n}=223)\end{array}$ & $\begin{array}{c}\text { Cluster 3 } \\
(\mathrm{n}=106)\end{array}$ \\
\hline Cluster name & Functional & Aggressive & Potential \\
\hline Cluster center & & & \\
Importance of bamboo & $\mathbf{4 . 5 3 3}$ & $\mathbf{4 . 9 9 2}$ & $\mathbf{4 . 0 5 3}$ \\
Profitability & 4.413 & 4.998 & 3.998 \\
Feasible & 4.479 & 4.990 & 3.988 \\
Acceptable & 4.474 & 4.990 & 4.005 \\
Available & 4.478 & 4.989 & 4.005 \\
Success & 4.699 & 4.991 & 4.267 \\
Perceived benefits & $\mathbf{4 . 2 6 7}$ & $\mathbf{4 . 9 9 6}$ & $\mathbf{4 . 1 3 6}$ \\
Economic & 4.224 & 5.000 & 4.110 \\
Social & 4.612 & 4.993 & 4.230 \\
Environment & 4.279 & 5.000 & 4.170 \\
Technology & 3.959 & 4.991 & 4.057 \\
Security & 4.259 & 4.998 & 4.113 \\
\hline
\end{tabular}

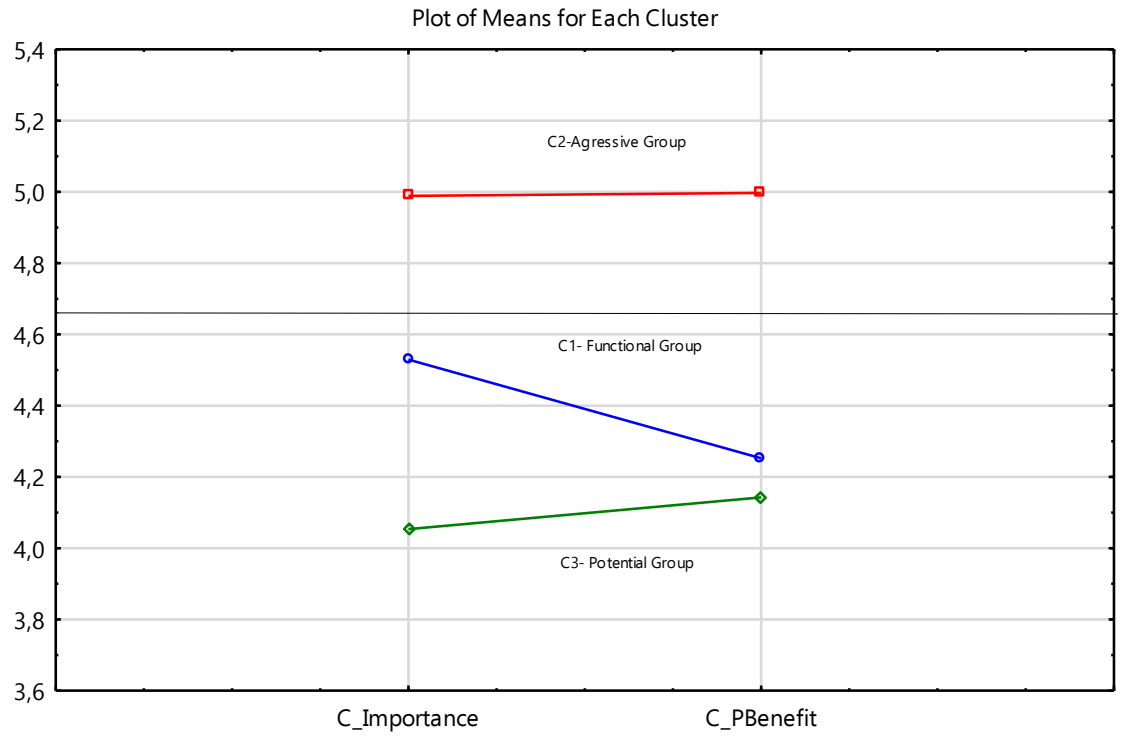

Figure 2. Means of each group of consumer's views

In Figure 2, each group given name based on the mean of each variable. Note that each case can identify the cluster it belongs to the importance of application and the perceived benefit factors. 
Cluster 1: Functional group

The first group ( $\mathrm{n}=49$ ) indicates an above average level ranging between 4.413 and 4.699 for the importance factor and 3.959 and 4.612 for the perceived benefit factor. Therefore, this cluster was name "Functional group". The group explain the consumers have knowledge about the importance of the application of bamboo but low benefit. Specifically, in this group, consumers have good understanding of items related to the importance of bamboo such as profitable, feasible, acceptable, available, and success. However, in this group, the awareness of the benefits of technology for bamboo products by consumers is still low (mean =3.959).

Therefore, manufacturers need to develop clear product introduction policies to improve consumers' knowledge about the benefits of bamboo products. The benefits bamboo products bring in terms of economy, society, environment, technology, and security. Manufacturers can promote the benefits of bamboo products through media such as local reality TV programs and social networks where consumers can easily find and access information. Moreover, manufacturers should establish craft villages or associations of manufacturers of bamboo products. Hence, it is possible to build a brand for bamboo products in Haiti. When bamboo products are of good quality and branded on the market, consumers will easily see the benefits of products made from bamboo. Beside, producers should increase the application of technology in bamboo products so that consumers can see the benefits of technology for products made from bamboo.

Cluster 2: Aggressive group

The second cluster $(n=223)$ is the group with high importance and high benefits factors, within the ranged between 4.989 and 4.998 for the importance application, and 4.991 and 5.000 for the perceived benefits. Hence, this cluster named "Aggressive group". It can be seen that consumers in this group have a perfect understanding of both the importance and benefits of bamboo. This group has the largest number of consumers. It can be see that the majority of consumers of bamboo products in Haiti have good understanding of the importance and benefits of bamboo. This is also a huge advantage for the consumption of bamboo products in Haiti. This is considered a potential group for the promotion of domestic and international consumption of bamboo products. Therefore, the local authorities should have policies to encourage consumers in this group who understand the importance and benefits of bamboo products, support the organization of promotion programs for the consumption of bamboo products.

\section{Cluster 3: Potential group}

The third cluster includes 106 consumers. This cluster with low importance application and low perceived benefits factors within between the range to 4.057 and 4.230 for the importance application factor and 3.988 and 4.267 to the benefits factor. Therefore, this cluster was name "Potential group". This is the group of consumers who have the lowest assessment of the importance and benefits of bamboo products. The profitable and feasible aspects are two aspects that consumers in this group have limited understanding of. The mean value of these two aspects is less than 4. These aspects are two important aspects that evaluate the importance of bamboo. Hence, it is necessary to have policies to improve understanding of the importance and benefits of bamboo for consumers in this group. Local governments should organize trade promotion programs to introduce bamboo products. Besides, production facilities, it is also necessary to pay attention to the quality, design of bamboo products, and 
reasonable prices so that consumers have confidence in bamboo products. Moreover, producers can enhance promotion programs about the beneficial and feasible aspects of bamboo through the media, social networks.

Figure 3 introduces a scatter which represents the center of each group as well as the characteristics, including their respective average for the important application and the perceived benefits. It should not be ignored however that within one group there are significant differences between members constituting the group. The bubbles are represented each group's achievement between clusters, therefore the better aggressive group of clusters for both important application and perceived benefit factors, the bigger bubble.

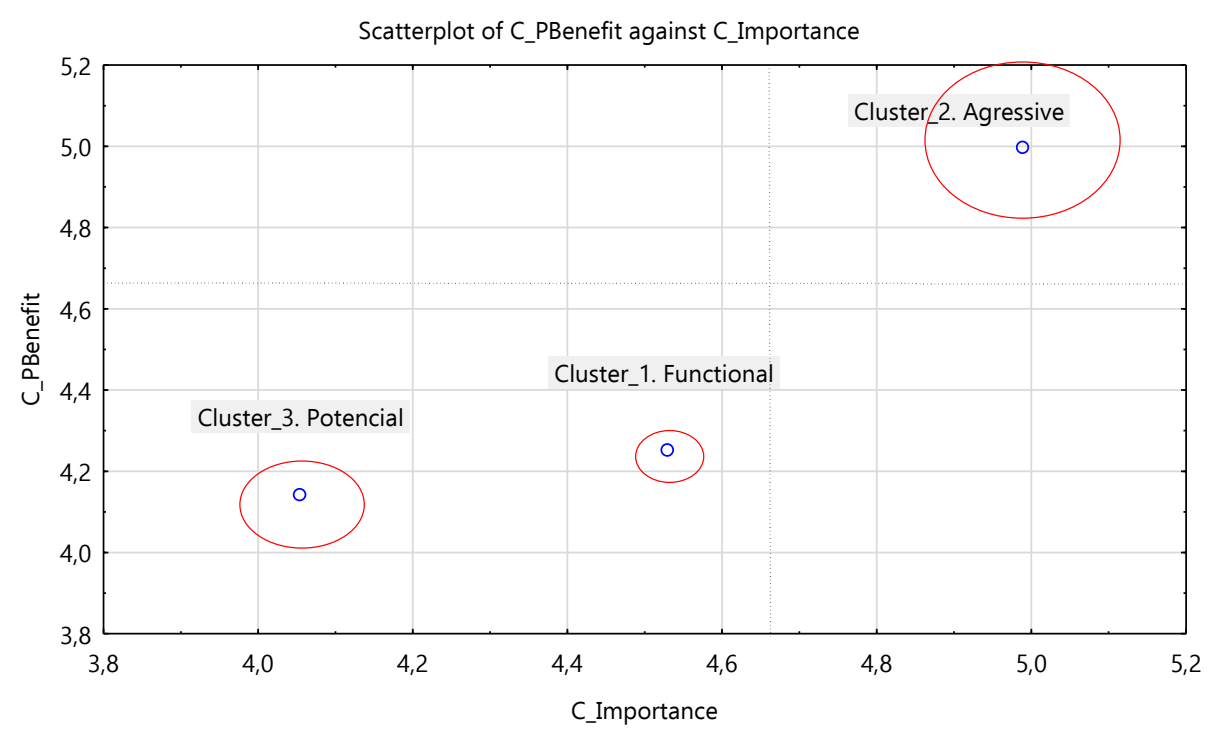

Figure 3. Cluster center and distribution of cases

\section{Conclusion}

The promotion of bamboo production can generally result from the cultivation and innovation of bamboo types likely to meet the material needs of consumers and beneficial. Today, bamboo products consume fewer resources and produce fewer types of applications. The diversity included in the production of raw materials also offers a way to promote sustainability in textile fashion (Yoo, Divita, \& Kim, 2013). In addition, awareness rising develops a better knowledge of bamboo made textiles also provide manufacturers with the necessary products. Adopt new materials especially used in construction. However, the best way to encourage companies to use sustainable textiles in their products is to highlight their long-term benefits and benefits, as well as new ways of solving environmental problems (Batalha et al., 2012). The objectives of this study are to identify and to classify the homogenous of cases that have similar need and knowledge about the importance of application and the perceived benefits. The results of this research indicated three clusters are formed; the first cluster is the functional group with high importance and low benefit, needed to increase the learning about the benefit of bamboo for accessibility and economic grows. The second cluster is the aggressive group within high importance of application and high benefit can facility the investment of promotion of bamboo product in the market. The third cluster is the profitable group need to improvement both of side because if the population have knowledge about the importance of the application of bamboo that unveils the advantages of bamboo to increase the profitability of this plant. More than the application is 
important, more than we make more money with this innovation and technology of bamboo production.

This research highlights for the population the cultivation of bamboo. So the production of bamboo can be very beneficial for the country both nationally and internationally. In the long term, it could export bamboo products to other countries and if the government invests in bamboo, it can benefit the country by attracting other investments in shares and invest in bamboo production. According to the different advantages of the bamboo especially for the country we can say that the technological development of the bamboo can be used as a source of energy and the breeding could have a better access to the electricity. Therefore, for the population in the zones if we cannot talk about water purification or housing, we can also help the country eliminate the phenomenon of tents. By definition of bamboo, we can conclude that the rapid growth of bamboo plantations could be an advantage for Haiti against deforestation.

\section{References}

Akwade, D., \& Akinlabi, E. T. (2016). Economic, social and environmental assessment of bamboo for infrastructure development. Agriculture, 12(4),167-174.

Batalha, L. A. R., Colodette, J., Gomide, J. L., Barbosa, L. C., Maltha, C. R., \& Gomes, F. J. J. B. (2012). Dissolving pulp production from bamboo. Bio Resources, 7(1), 06400651.

Ben-zhi, Z., Mao-yi, F., Jin-zhong, X., Xiao-sheng, Y., \& Zheng-cai, L. (2005). Ecological functions of bamboo forest: Research and Application. Journal of Forestry Research, 16(2), 143-147. doi:10.1007/BF02857909

Chen, D., Zhou, J., \& Zhang, Q. (2014). Effects of heating rate on slow pyrolysis behavior, kinetic parameters and products properties of moso bamboo. Bioresource Technology, 169, 313-319.

Darabant, A., Rai, P. B., Staudhammer, C. L., \& Dorji, T. (2016). Designing and Evaluating Bamboo Harvesting Methods for Local Needs: Integrating Local Ecological Knowledge and Science. Environ Manage, 58(2), 312-322. doi:10.1007/s00267-0160702-6

Dayawansa, H. (2012). Sri Lanka kicks off first ever bamboo processing initiative. Celon Development, 9(2), 136-146.

Francois, D., \& Liaw, S.-Y. (2019). Important Applications and the Perceived Benefits of Bamboo: A Comparison between Consumers and Businessmen. International journal of business and management, 14(6), 1-17.

Ganado, L., Undan, J., \& Valentino, M. (2016). Proximate composition and cytotoxicity of single cell protein enriched rich bran. Current Research in Environmental \& Applied Mycology, 6(2), 102-110.

Hair, Black, W. C., Babin, B. J., \& Anderson, R. E. (2014). Multivariate_data_analysis. Peason. 
Vol. 2, No. 3, August 2021

Henseler, J., Ringle, C. M., \& Sinkovics, R. R. (2009). The use of partial least squares path modeling in international marketing. In New challenges to international marketing. Emerald Group Publishing Limited, 20, 277-319.

Hu, X., \& Xu, L. (2003). A Comparative Study of Several Cluster Number Selection Criteria. Paper presented at the Intelligent Data Engineering and Automated Learning, Berlin, Heidelberg.

Lobovikov, M. (2003). Bamboo and rattan products and trade. Journal of Bamboo and Rattan, 2(4), 397-406.

Lobovikov, M., Schoene, D., \& Yping, L. (2012). Bamboo in climate change and rural livelihoods. Mitigation and Adaptation Strategies for Global Change, 17(3), 261-276.

McNeely, J. A. (1999). Biodiversity and bamboo genetic resources in Asia: in situ, community-based and ex situ approaches to conservation. Biodiversity Science, 7(1), $38-51$.

Mudjanarko, S. W., \& Mayestino, M. (2017). Engineering Technology Of Bamboo Material And Additive Foam Concrete As Mixed Material Testing On Paving Production. JURNAL LENTERA: Kajian Keagamaan, Keilmuan Dan Teknologi, 3(2).

Nunnally, J. C., \& Bernstein, I. (1994). Psychometric Theory (McGraw-Hill Series in Psychology) (Vol. 3): McGraw-Hill New York.

Ogunwusi, A. (2013). Bamboo: an alternative raw material for textiles production in Nigeria. Chemistry and Materials Research, 3(11), 6-18.

Pandey, C., \& Shyamasundar, K. (2008). Post harvest management and storage of bamboo culms. Paper presented at the Proceedings of the International Conference on Improvement of Bamboo productivity and marketing for sustainable livelihood. 15th17th April.

Phimmachanh, S., Ying, Z., \& Beckline, M. (2015). Bamboo resources utilization: A potential source of income to support rural livelihoods. Applied Ecology and Environmental Sciences, 3(6), 176-183.

Rockström, J., Steffen, W., Noone, K., Persson, Å., Chapin III, F. S., Lambin, E. F., . . . Schellnhuber, H. J. (2009). A safe operating space for humanity. nature, 461(7263), 472.

Scurlock, J. M. O., Dayton, D. C., \& Hames, B. (2000). Bamboo: an overlooked biomass resource? Biomass and Bioenergy, 19(4), 229-244. doi:https://doi.org/10.1016/S09619534(00)00038-6.

Singh, O. (2008). Bamboo for sustainable livelihood in India. Indian Forester, 134(9), 11931198.

Yoo, J.-J., Divita, L., \& Kim, H.-Y. (2013). Environmental awareness on bamboo product purchase intentions: do consumption values impact green consumption? International Journal of Fashion Design, Technology and Education, 6(1), 27-34. doi:10.1080/17543266.2012.758318.

Zhaohua, L., \& Kobayashi, M. (2004). Plantation future of bamboo in China [J]. Journal of Forestry Research, 15(3), 233-242. 


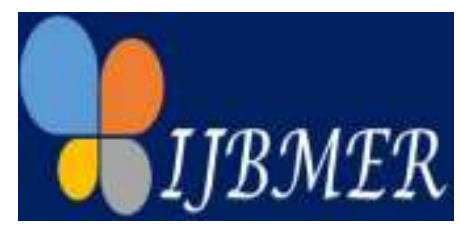

International Journal of Business, Management \& Economics e-ISSN: 2746-1351

Vol. 2, No. 3, August 2021

\section{Copyrights}

Copyright for this article is retained by the author(s), with first publication rights granted to the journal.

This is an open-access article distributed under the terms and conditions of the Creative Commons Attribution license (http://creativecommons.org/licenses/by/4.0/)

\section{Appendix 1: 20 applications of Bamboo}

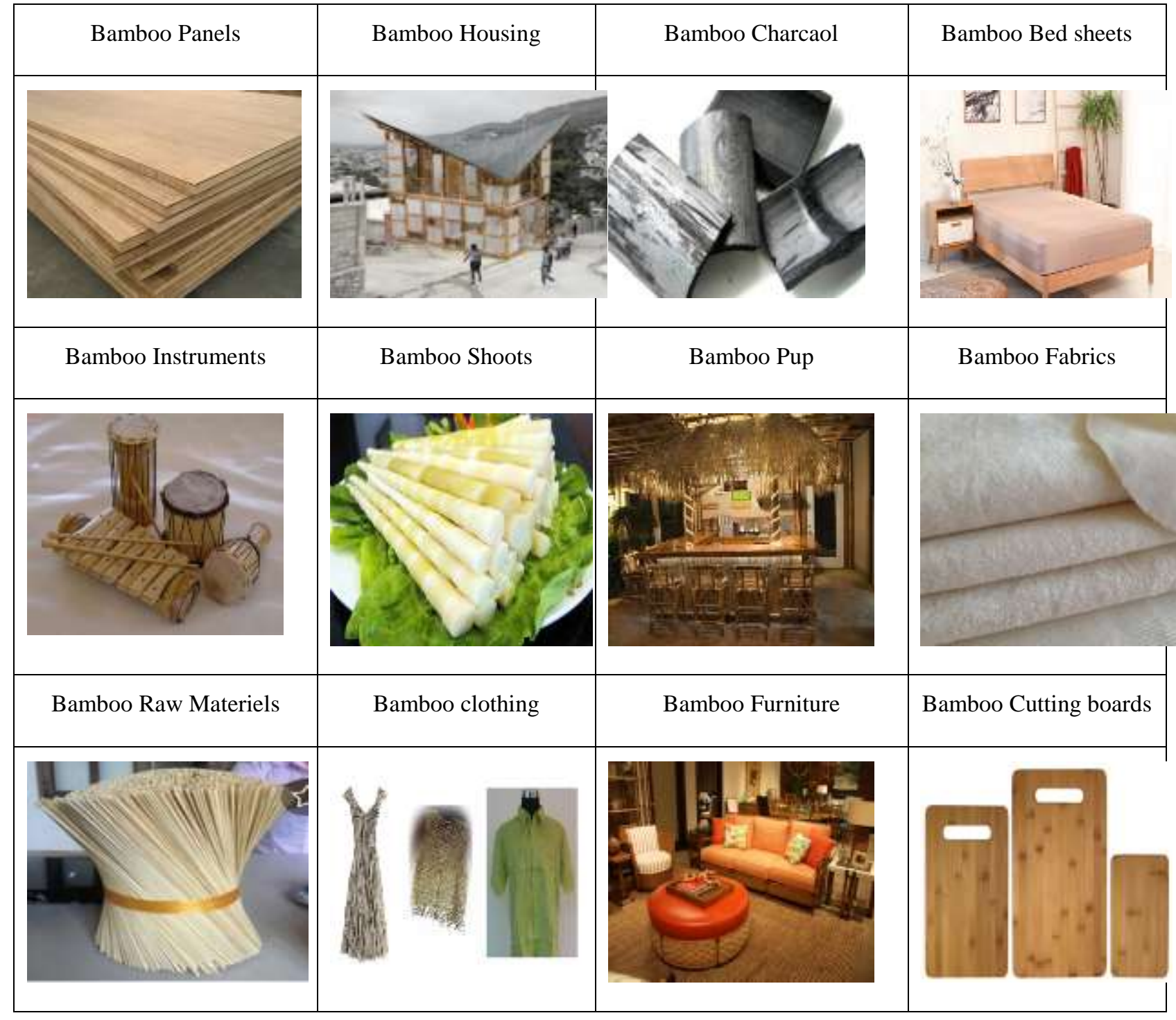

Published by: 


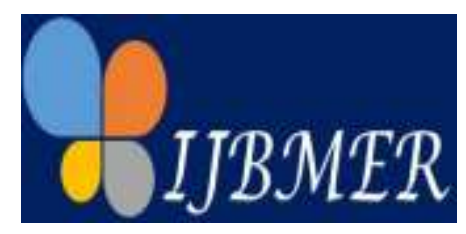

International Journal of Business, Management \& Economics

e-ISSN: 2746-1351

Vol. 2, No. 3, August 2021

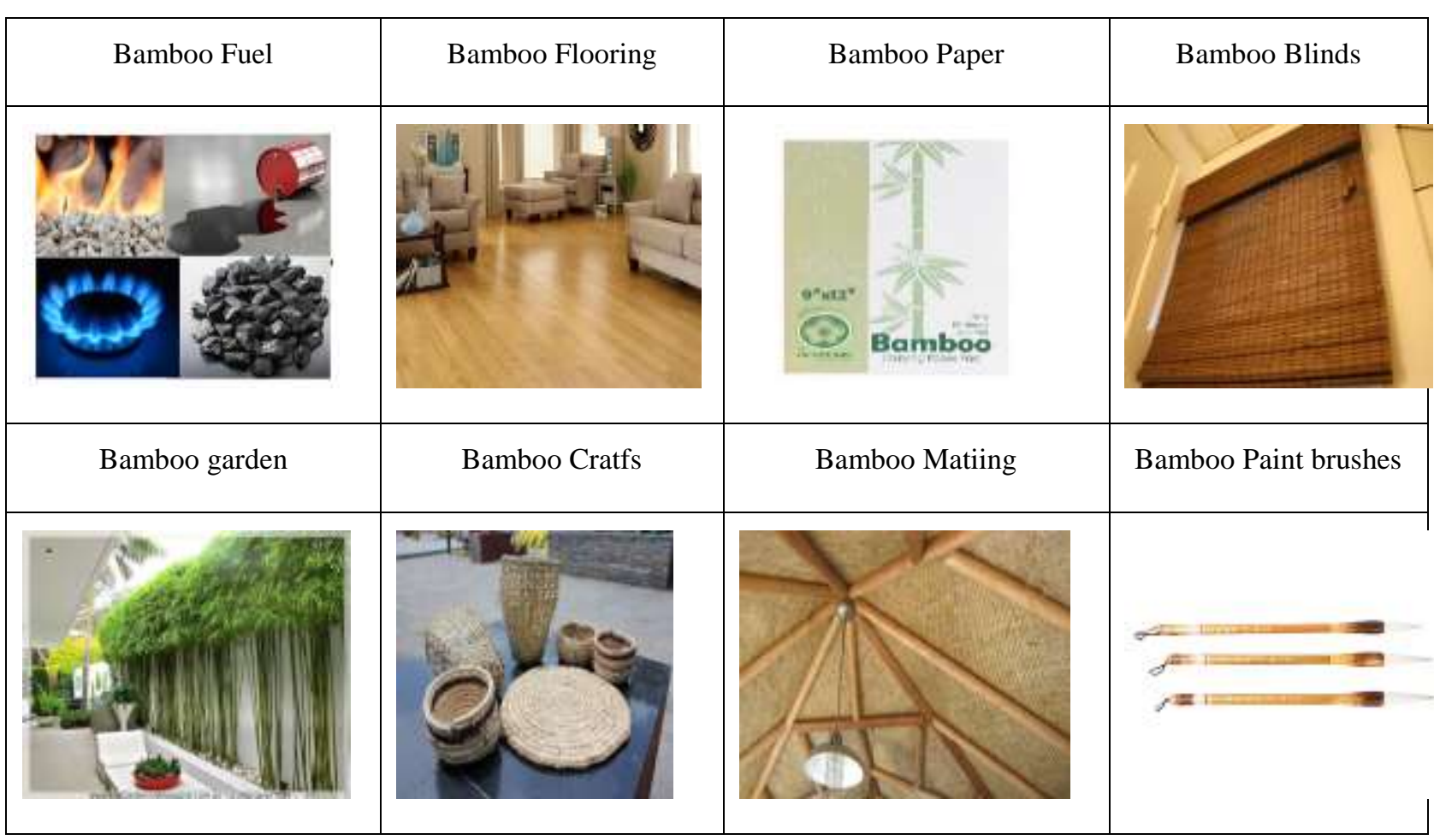

Published by: 